\title{
Bioprospecting of Novel and Bioactive Metabolites from Endophytic Fungi Isolated from Rubber Tree Ficus elastica Leaves ${ }^{\mathbb{S}}$
}

\author{
Zhuang Ding ${ }^{1 *}$, Tao Tao ${ }^{1}$, Lili Wang ${ }^{1}$, Yanna Zhao ${ }^{1}$, Huiming Huang ${ }^{2}$, Demeng Zhang ${ }^{3}$, Min Liu ${ }^{1}$, Zhengping Wang ${ }^{1}$, \\ and Jun Han ${ }^{1}$ \\ ${ }^{1}$ Institute of BioPharmaceutical Research, Liaocheng University, Liaocheng, 252059, P.R. China \\ ${ }^{2}$ School of Life Sciences, Liaocheng University, Liaocheng, 252059, P.R. China \\ ${ }^{3}$ State Key Laboratory of Bioactive Seaweed Substances, Qingdao Bright Moon Seaweed Group Co. Ltd., Qingdao, 266400, P.R. China
}

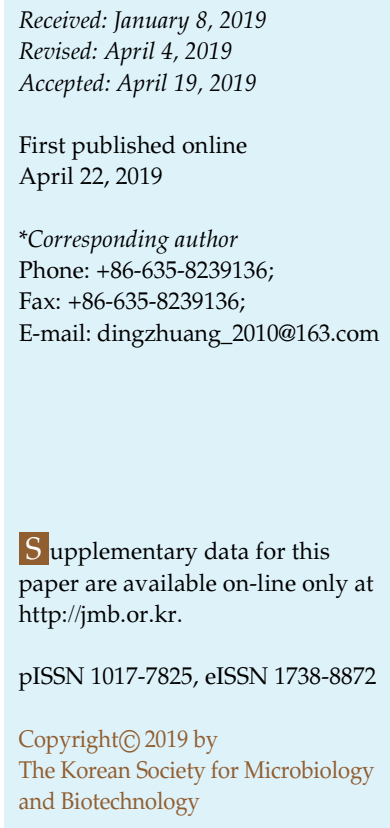

S upplementary data for this paper are available on-line only at http://jmb.or.kr.

pISSN 1017-7825, eISSN 1738-8872

Copyright(C) 2019 by

The Korean Society for Microbiology and Biotechnology

Endophytic fungi are an important component of plant microbiota, and have the excellent capacity for producing a broad variety of bioactive metabolites. These bioactive metabolites not only affect the survival of the host plant, but also provide valuable lead compounds for novel drug discovery. In this study, forty-two endophytic filamentous fungi were isolated from Ficus elastica leaves, and further identified as seven individual taxa by ITS-rDNA sequencing. The antimicrobial activity of these endophytic fungi was evaluated against five pathogenic microorganisms. Two strains, Fes1711 (Penicillium funiculosum) and Fes1712 (Trichoderma harzianum), displayed broad-spectrum bioactivities. Our following study emphasizes the isolation, identification and bioactivity testing of chemical metabolites produced by T. harzianum Fes1712. Two new isocoumarin derivatives ( $\mathbf{1}$ and $\mathbf{2})$, together with three known compounds (3-5) were isolated, and their structures were elucidated using NMR and MS. Compounds $\mathbf{1}$ and $\mathbf{2}$ exhibited inhibitory activity against Escherichia coli. Our findings reveal that endophytic fungi from the rubber tree F. elastica leaves exhibit unique characteristics and are potential producers of novel natural bioactive products.

Keywords: Antimicrobial activity, endophytic fungi, Trichoderma harzianum, isocoumarin, metabolites, Ficus elastica

\section{Introduction}

Endophytic fungi are generally regarded as the fungal microorganisms colonizing the internal tissues of healthy plants without causing any apparent negative effects. These fungi are ubiquitously found in most plant species studied so far and exist in various tissues of host plants, such as roots, stems, leaves, flowers, fruits and seeds [1]. Complex interactions exist between endophytic fungi and host plants [2], and many endophytic fungi are considered as beneficial for their hosts in many ways, including promoting host growth and nutrient gain [3], as well as enhancing host resistance to phytopathogens, pests or abiotic stress [4].

In long-term symbioses with their host plants, many endophytes could produce bioactive secondary metabolites to exert positive influence on their hosts [5]. It has been surmised that endophytic fungi and host plants have similar biosynthesis pathways to produce secondary metabolites due to horizontal gene transfer, especially after the discovery of paclitaxel (taxol) in the endophytic fungus Taxomyces andreanae [6, 7]. Subbulakshmi et al. also proposed that microorganisms associated with host plants rather than plants themselves provided bioactive metabolites with high therapeutic potential [8]. As a characteristic bioresource, endophytic fungi have become an important reservoir to exploit novel bioactive metabolites. A large number of novel secondary metabolites isolated from endophytic fungi have been reported as potential agricultural and/or pharmaceutical candidates for antimicrobial, anticancer, anti-inflammatory, and many more bioactivities $[9,10]$. And yet, it is believed that only $5 \%$ of the global 
fungi have been identified so far, which suggests that a great many new bioactive natural products from endophytic fungi remain to be explored [11].

Over 2000 species of higher plants make latex, though only a few laticiferous plants have been exploited commercially, such as Hevea brasiliensis and Ficus elastica. F. elastica, also known as the Indian rubber tree, is an evergreen plant of tropical Asia that is grown for rubber production [12]. Now, it is grown around the world as an ornamental plant, outside in frost-free climates from the tropics to the Mediterranean and inside in colder climates as a houseplant. However, only a few studies have been focused on the endophytes from F. elastica. Solis et al. have reported on the diversity patterns of leaf-inhabiting endophytic yeasts of three tropical Ficus species collected from botanical garden greenhouses in Germany [13]. Although plenty of research has been conducted on the bioactive natural products synthesized by endophytic fungi from various plants, the bioactive secondary metabolites of endophytic fungi from $F$. elastica have never been investigated. In this study, we selected leaves of F. elastica to investigate preliminary characterization of the endophytic fungi. Furthermore, the antimicrobial activities of the identified endophytes were also assayed. Finally, we purified and identified the bioactive constituents present in the highly-active endophyte Trichoderma harzianum.

\section{Methods and Materials}

\section{Sample Collection and Isolation of Endophytic Fungi}

Fresh leaves of F. elastica were collected in October 2017, from Liaocheng University Arboretum, Liaocheng, Shandong, China. The samples were placed in disinfected individual plastic bags and transferred to the laboratory. The samples were rinsed with tap water and surface sterilized by immersion in $2 \%$ sodium hypochlorite for $3 \mathrm{~min}, 70 \%$ ethanol for $2 \mathrm{~min}$, and washed with sterile water. The leaf pieces $(5 \times 5 \mathrm{~mm})$ were cut from the processed samples and placed on Petri plates containing potato dextrose agar (PDA). The plates were incubated at $25{ }^{\circ} \mathrm{C}$ until hyphae emerged from the cut ends. The hyphal tips were restreaked and subcultured on a new PDA plate. This restreaking process was repeated until pure morphotype colonies were obtained. The strains were sorted into morpho-species according to their appearance (colony color and texture, border type, and radial growth rate) on PDA medium.

\section{Molecular Identification of the Strains}

Total DNA was extracted from each strain following the protocol described by Ding et al. [14]. The internal transcribed spacer region of rDNA (ITS1-5.8S-ITS2) was amplified with the universal primers ITS1 (5'-TCCGTAGGTGAACCTGCGG-3') and
ITS4 (5'-TCCTCCGCTTATTGATATGC-3'). Details of PCR reaction can be found in Sharma et al. [15]. The PCR products were purified and sequenced by Sangon Biotech Co. Ltd. (China). The sequences identified were compared with other sequences in the GenBank database (http://www.ncbi.nlm.nih.gov) by BLAST analysis. Sequence data in this study were deposited in GenBank under the accession numbers MK240330-MK240336.

\section{Fermentation and Extract Preparation}

The endophytic fungal strains were cultured using PDA solid medium at $25^{\circ} \mathrm{C}$ for 5 days. Subsequently, $5 \mathrm{~mm}$ diameter plugs with adhering mycelia were added to $250 \mathrm{ml}$ flasks containing $100 \mathrm{ml}$ of potato dextrose broth (PDB) medium. All cultures were grown under shaking condition at $180 \mathrm{rpm}$ and $25^{\circ} \mathrm{C}$ for 7 days. Each test contained five replicates for each strain.

The fermentation extracts were processed following the protocols established by Ding et al. [14]. After cultivation, the mycelia in the fermentation mixture were broken up using a disperser (T18, IKA, Germany), then the fermentation mixture was extracted with an equal volume of ethyl acetate (EtOAc). The extracts were evaporated under reduced pressure and redissolved by $\mathrm{MeOH}$. Sterile PDB medium was extracted using the same procedure. The sterile PDB extract was used as the control in the screening procedure.

\section{Metabolite Fingerprint Analysis}

The extracts were analyzed in a HPLC system (Waters Inc., USA), which contained a model 1525 pump, a model 2489 UV detector, and a HPLC column (Pack ODS-A, $250 \times 4.6 \mathrm{~mm}, 5 \mu \mathrm{m}$, YMC Co., Ltd., Japan). The gradient increased from 10 to $100 \%$ $\mathrm{MeOH}$ over $30 \mathrm{~min}$ and was retained at $100 \%$ for $10 \mathrm{~min}$.

\section{Purification and Identification of Natural Products}

Large-scale culture $(10 \mathrm{~L})$ and extract preparation of the strain Lcu-Fe1712 were performed in PDB liquid medium using the method mentioned above. $2.7 \mathrm{~g}$ of the EtOAc extract was gained and separated by silica gel vacuum liquid chromatography using $\mathrm{CH}_{2} \mathrm{Cl}_{2}-\mathrm{MeOH}$ (20:1) to give five fractions (Fractions 1 to 5). Fraction 2 was further separated by Sephadex LH-20 chromatograph eluted with $\mathrm{CH}_{2} \mathrm{Cl}_{2}-\mathrm{MeOH}$ (1:1) and then on a semi-preparative HPLC column (Pack ODS-A, $250 \times 10$ mm, $5 \mu \mathrm{m}$, YMC Co., Ltd.) eluted with $\mathrm{MeOH}-\mathrm{H}_{2} \mathrm{O}(80: 20,3 \mathrm{ml} / \mathrm{min})$ to provide compound 4 $\left(5.6 \mathrm{mg}, t_{\mathrm{R}} 10.5 \mathrm{~min}\right)$ and compound $5\left(20.2 \mathrm{mg}, t_{\mathrm{R}} 12.0 \mathrm{~min}\right)$. Fraction 3 was further separated on a Sephadex LH-20 column with $\mathrm{MeOH}$ to provide three subfractions (fractions 3-1 to 3-3). Fraction 3-2 was separated by semi-preparative HPLC eluted with MeOH- $\mathrm{H}_{2} \mathrm{O}$ (56:36, $\left.3 \mathrm{ml} / \mathrm{min}\right)$, to obtain compound 1 (2.7 mg, $t_{\mathrm{R}}$ $12.5 \mathrm{~min})$, compound $2\left(3.2 \mathrm{mg}, t_{\mathrm{R}} 15.5 \mathrm{~min}\right)$ and compound 3 (6.2 $\left.\mathrm{mg}, t_{\mathrm{R}} 23.5 \mathrm{~min}\right)$.

The structures of the compounds were elucidated from extensive MS and NMR. High-resolution electrospray ionization MS (HRESI-MS) spectra were measured on a Micromass EI-4000 Autospec-Ultima-TOF (Micromass communication Inc., UK). 
Table 1. Endophytic fungi isolated from Ficus elastica as identified by ITS sequences.

\begin{tabular}{cccccc}
\hline $\begin{array}{c}\text { Strain } \\
\text { number }\end{array}$ & $\begin{array}{l}\text { Closest BLAST match } \\
\text { [GenBank accession number] }\end{array}$ & Query coverage (\%) & Identity (\%) & $\begin{array}{c}\text { No. of bp } \\
\text { analyzed }\end{array}$ & $\begin{array}{c}\text { Identification } \\
\text { [GenBank accession number] }\end{array}$ \\
\hline Fes1714 & $\begin{array}{l}\text { Penicillium aeneum } \\
\text { [KP016812] } \\
\text { Penicillium chrysogenum }\end{array}$ & 100 & 100 & 516 & Penicillium aeneum \\
[JN851002] & 100 & 99 & 523 & Penicillium chrysogenum \\
Fes1711 & $\begin{array}{l}\text { Penicillium funiculosum } \\
\text { [GQ337426] } \\
\text { Penicillium variabile }\end{array}$ & 100 & 100 & 517 & Penicillium funiculosum \\
Fes1703 & $\begin{array}{l}\text { [HQ288049] } \\
\text { Scytalidium lignicola } \\
\text { [MH863583] }\end{array}$ & 100 & 99 & 535 & Penicillium variabile \\
Fes1712 & $\begin{array}{l}\text { Trichoderma harzianum } \\
\text { [KM078037] } \\
\text { Zasmidium anthuriicola }\end{array}$ & 99 & 93 & 528 & Scytalidium sp. \\
Fes1702 & 100 & 100 & 551 & Trichoderma harzianum \\
\hline [MH863035] & 100 & 99 & 315 & Zasmidium anthuriicola \\
\hline
\end{tabular}

NMR spectra were recorded on a Varian 500 spectrometer (Varian Medical Systems Inc., USA) using tetramethylsilane as an internal standard, and chemical shifts were recorded as $\delta$ values.

\section{Bioactive Assays}

Antimicrobial activity of the extracts were evaluated by the well diffusion method. The five microorganisms indicated were the bacteria Bacillus subtilis CMCC 63501, Escherichia coli CMCC 44102, Pseudomonas aeruginosa CMCC 10104, Staphylococcus aureus CMCC 26003, and the fungus Candida albicans CMCC 98001. The above strains were obtained from the China General Microbiological Culture Collection Center. $100 \mu \mathrm{l}$ of the microorganism suspensions at a density of $10^{6}$ cells $\mathrm{ml}^{-1}$ were seeded onto corresponding medium plates. The crude extracts were dissolved in $\mathrm{MeOH}$ to a concentration of $1 \mathrm{mg} / \mathrm{ml}$. The pure compounds were serially diluted in $\mathrm{MeOH}$ from $256 \mu \mathrm{g} / \mathrm{ml}$ to $1 \mu \mathrm{g} / \mathrm{ml}$. $10 \mu \mathrm{l}$ of the solutions were added to $6.0 \mathrm{~mm}$ paper disks, which were placed on the plates. Antibacterial chloramphenicol $(0.1 \mathrm{mg} / \mathrm{ml})$ was used as a positive control for bacteria and antifungal fluconazole $(0.1 \mathrm{mg} / \mathrm{ml})$ was used for yeast. The assay plates were incubated for $24 \mathrm{~h}$ at $37^{\circ} \mathrm{C}$, then the diameter of the growth inhibition zone was measured.

\section{Results}

\section{Isolation, Identification and Bioactivity of the Endophytic Fungi}

A total of 42 endophytic fungi were isolated from healthy leaves of Ficus elastica. After being dereplicated by morphological characteristics (Fig. S1), only seven strains were retained and preserved at the Clinical Nutrition

Table 2. Bioactivities of the metabolites from endophytic fungi associated with Ficus elastica.

\begin{tabular}{lccccc}
\hline \multirow{2}{*}{ Strain number } & \multicolumn{5}{c}{ Antimicrobial activity: $(\mathrm{mm})^{\mathrm{a}}$} \\
\cline { 2 - 6 } Fes1701 & B. subtilis & C. albicans & E. coil & P. aeruginosa & S. aureus \\
Fes1702 & - & $9.6 \pm 2.0$ & - & - & $10.3 \pm 0.7$ \\
Fes1703 & - & - & - & - & - \\
Fes1707 & - & - & - & - & - \\
Fes1711 & - & - & - & - & $15.9 \pm 2.5$ \\
Fes1712 & - & $10.4 \pm 1.7$ & $16.5 \pm 1.6$ & - & $15.7 \pm 1.7$ \\
Fes1714 & - & $9.0 \pm 1.2$ & $18.5 \pm 2.2$ & $9.1 \pm 2.2$ & $9.2 \pm 2.5$ \\
Chloramphenicol $^{\mathrm{b}}$ & - & - & $10.7 \pm 3.3$ & - & $21.0 \pm 1.5$ \\
Fluconazole $^{\mathrm{b}}$ & $17.9 \pm 1.1$ & - & $26.1 \pm 0.8$ & $9.7 \pm 1.6$ & - \\
\hline
\end{tabular}

${ }^{a}$ Antimicrobial activity was estimated by the inhibitory zone $(\mathrm{mm})$ to five indicator microorganisms. The diameter of the inhibition zone: $>15 \mathrm{~mm}$ is intense (bold), $9-$ $15 \mathrm{~mm}$ is medium, $<9 \mathrm{~mm}$ is low/no activity and not shown. Indicator microorganisms: B. subtilis, Bacillus subtilis CMCC 63501; C. albicans, Candida albicans CMCC 98001; E. coil, Escherichia coli CMCC 44102; P. aeruginosa, Pseudomonas aeruginosa CMCC 10104; S. aureus, Staphylococcus aureus CMCC 26003. The crude extracts at concentration of $1 \mathrm{mg} / \mathrm{ml}$ were used in the evaluation of antimicrobial activities.

${ }^{\mathrm{b}}$ Antibacterial chloramphenicol $(0.1 \mathrm{mg} / \mathrm{ml})$ and antifungal fluconazole $(0.1 \mathrm{mg} / \mathrm{ml})$ were used as positive controls. 
<smiles>COc1cc(O)c2c(=O)oc(C(O)C(O)CO)cc2c1</smiles>

1<smiles>COc1cc(O)c2c(=O)oc(CC(O)C(O)O)cc2c1</smiles>

2<smiles>COc1cc(O)c2c(=O)c(CO)c(C)oc2c1</smiles>

3<smiles>COc1cc(O)c2c(=O)c(C)c(C)oc2c1</smiles>

4<smiles>COc1cc(C)c2c(=O)c3c(O)cc(OC)cc3oc2c1</smiles>

5

Fig. 1. Chemical structures of isolated compounds 1-5 from T. harzianum Fes1712.

Research Center, Liaocheng University, China. These strains were further identified taxonomically based on ITS-rDNA sequences, and assigned to seven individual taxa belonging to the genera Penicillium, Scytalidium, Trichoderma, and Zasmidium (Table 1).

The antimicrobial activity of the EtOAc extracts of endophytic fungi isolated from F. elastica were evaluated against five pathogenic microorganisms. Results showed that strains Fes1702, Fes1703 and Fes1707 exhibited no inhibitory bioactivity against any of the tested microorganisms, while the other four crude extracts included biologically active compounds against at least one of the tested microorganisms (Table 2). P. funiculosum Fes1711 and T. harzianum Fes1712 exhibited intense inhibitory activity against both the Gram-negative bacteria E. coli and Gram-positive bacterial strain $S$. aureus, while the former also showed stronger inhibitory activity to the fungus C. albicans more than any other strain. In addition, only T. harzianum Fes1712 exhibited equivalent inhibitory activity to the Gram-positive bacteria P. aeruginosa when compared to the positive drug.

\section{Purification, Structural Identification and Bioactivities of the Metabolites from Strain Fes1712}

Due to its great antimicrobial activity, the endophyte strain Fes1712 was selected for further chemical investigation using its EtOAc extract. Two new isocoumarin derivatives (1 and 2), together with three known compounds (3-5) were isolated from the fermentation extract. Structures of these compounds were determined using MS analyses and NMR methods (Fig. 1).

Compound (1) was isolated as a white solid powder and had the molecular formula $\mathrm{C}_{13} \mathrm{H}_{14} \mathrm{O}_{7}$ as determined by the HRESI-MS peak $\left([\mathrm{M}+\mathrm{Na}]^{+}\right.$at $m / z$ 305.0624) (Fig. S2). The 1D NMR data (Table 3) showed 13 carbon signals, which were classified by distortionless enhancement by polarization transfer (DEPT) and heteronuclear single quantum coherence (HSQC) spectra as six nonprotonated carbons including four esters or enol ketones and two sp2 hybridized carbons, five methines including two oxygenated and three sp2 hybridized carbons, one oxygenated methylene and one oxygenated methyl (Figs. S3-S6). The

Table 3. ${ }^{1} \mathrm{H}$ and ${ }^{13} \mathrm{C}$ NMR data of Compounds 1 and 2 (500 MHz in $\left.\mathrm{CDCl}_{3}\right)$; $\delta$ in p.p.m., J in Hz.

\begin{tabular}{lllll}
\hline \multirow{2}{*}{ Position } & \multicolumn{2}{c}{ Compound (1) } & \multicolumn{2}{c}{ Compound (2) } \\
\cline { 2 - 5 }$\delta_{\mathrm{C}}$ & \multicolumn{1}{c}{$\delta_{\mathrm{H}}$} & $\delta_{\mathrm{C}}$ & \multicolumn{1}{c}{$\delta_{\mathrm{H}}$} \\
\hline 1 & $165.1(s)$ & & $165.9(s)$ \\
3 & $150.8(s)$ & & $152.8(s)$ & \\
4 & $108.4(d)$ & $6.55(s)$ & $106.4(d)$ & $6.57(s)$ \\
$4 \mathrm{a}$ & $137.7(s)$ & & $138.8(s)$ & \\
5 & $103.0(d)$ & $6.41(s)$ & $100.9(d)$ & $6.44(d, J=2.10)$ \\
6 & $167.0(s)$ & & $166.5(s)$ & \\
7 & $101.6(d)$ & $6.54(s)$ & $100.2(d)$ & $6.47(s)$ \\
8 & $163.89(s)$ & & $162.5(s)$ & \\
$8 \mathrm{a}$ & $100.4(s)$ & & $99.2(s)$ & \\
9 & $57.7(d)$ & $4.66(d, J=8.85)$ & $35.3(t)$ & $3.03(d d, J=14.90,3.4)$ \\
& & & & $2.83(d d, J=14.90,9.15)$ \\
10 & $71.2(d)$ & $4.49(m)$ & $72.3(d)$ & $4.38(m)$ \\
11 & $47.2(t)$ & $4.05(d, J=11.80)$ & $75.1(d)$ & $5.92(d, J=3.4)$ \\
& & $3.96(d, J=11.75)$ & & \\
$6-O C H 3$ & $55.8(q)$ & $3.87(s)$ & $55.0(q)$ & $3.89(s)$ \\
\hline
\end{tabular}



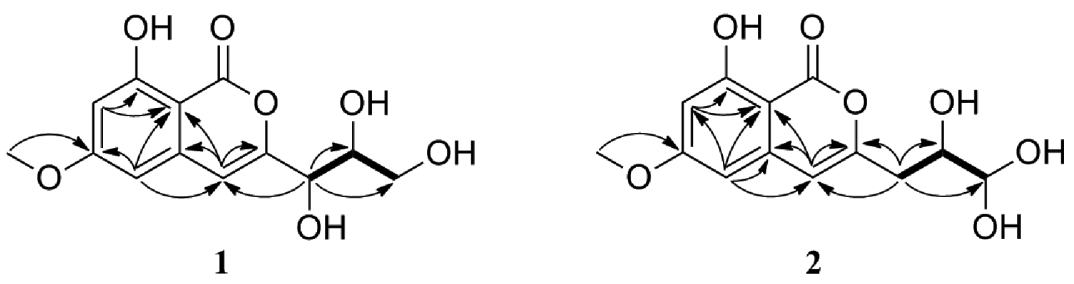

Fig. 2. Key COSY and HMBC correlations of 1 and 2.

chemical shifts of C-1 - C-8a indicated the presence of an isocoumarin moiety, which was further validated by the heteronuclear multiple bond correlation (HMBC) (Fig. 2). The ${ }^{1} \mathrm{H}-{ }^{1} \mathrm{H}$ correlation spectroscopy (COSY) (H-9/H-10/ $\mathrm{H} 2-11)$ and the HMBC from $\mathrm{H}-9$ to $\mathrm{C}-10 / \mathrm{C}-11$ and from $\mathrm{H}-$ 11 to $\mathrm{C}-9$, as well as the chemical shifts of C-9 $-\mathrm{C}-11\left(\delta_{\mathrm{C}}\right.$ $57.7 / \delta_{\mathrm{H}} 4.66, \mathrm{CH}-9 ; \delta_{\mathrm{C}} 71.2 / \delta_{\mathrm{H}} 4.49, \mathrm{CH}-10 ; \delta_{\mathrm{C}} 47.2 / \delta_{\mathrm{H}} 4.05$, 3.96, $\left.\mathrm{CH}_{2}-11\right)$, suggested the existence of a butanetriol residue (Figs. S7-S8). The butanetriol residue was linked with the isocoumarin moiety, as evidenced by the HMBC correlation from H-9 to C-4. The planar structure of 1 was thus established and shown in Fig. 1.

Compound (2) was obtained as a white powder with the same molecular formula as that of $\mathbf{1}$ (Fig. S9). Similarly, the 1D and 2D NMR data of 2 (Table 3, Figs. S10-S15) showed that it shared the same isocoumarin skeleton as 1 . The differences between the observed compounds 1 and 2 were the substitutional positions of hydroxyl groups in the butanetriol residue, shown as the replacement of the 1,2,3butanetriol group in 1 by a 1,1,2-butanetriol group $\left(\delta_{\mathrm{C}}\right.$ $35.3 / \delta_{\mathrm{H}} 3.03,2.83, \mathrm{CH}_{2}-9 ; \delta_{\mathrm{C}} 72.3 / \delta_{\mathrm{H}} 4.38, \mathrm{CH}-10 ; \delta_{\mathrm{C}} 75.1 / \delta_{\mathrm{H}}$ $5.92, \mathrm{CH}-11)$ in 2. However, due to lack of samples, the configurations of $\mathbf{1}$ and $\mathbf{2}$ were not determined.

In addition, the other three known compounds (3-5) were also isolated. By comparison with the published spectroscopic data in the literature (Figs. S16-S21), their structures were identified as 5-hydroxy-3-hydroxymethyl2-methyl-7-methoxychromone (3), 5-hydroxy-2,3-dimethyl7-methoxychromone (4), lichexanthone (5), respectively.

The antimicrobial activity of the purified compounds in this study were further investigated (Table 4). Compounds $\mathbf{1}$ and $\mathbf{2}$ exhibited growth inhibitory activity against E. coli with MIC values of $32 \mu \mathrm{g} / \mathrm{ml}$. Compound 3 showed the highest antifungal activity against C.albicans with MIC values of $128 \mu \mathrm{g} / \mathrm{ml} .128 \mu \mathrm{g} / \mathrm{ml}$ of lichexanthone (5) exhibited the broad-spectrum antibacterial activity against $B$. subtilis, $P$. aeruginosa and $S$. aureus.

\section{Discussion}

In this study, the diversity characterization and bioactivities of cultivable fungi isolated from fresh leaves of F. elastica were investigated. A total of 42 cultivable fungal colonies were isolated and identified as seven individual taxa, that indicated low abundance and diversity of fungal communities in F. elastica. In the bioactivities assay, we screened the antimicrobial activity of EtOAc extracts of seven fungal strains, of which two exhibited significant activities.

Three strains of Penicillium species in this study exhibited

Table 4. MIC values of the isolated compounds evaluated against the tested microorganisms.

\begin{tabular}{|c|c|c|c|c|c|}
\hline \multirow{2}{*}{ Compound } & \multicolumn{5}{|c|}{ Strains, MIC $(\mu \mathrm{g} / \mathrm{ml})$} \\
\hline & B. subtilis & C. albicans & E. coil & P. aeruginosa & S. aureus \\
\hline 1 & $>256$ & 256 & 32 & 128 & 128 \\
\hline 2 & $>256$ & 256 & 32 & 128 & 128 \\
\hline 3 & $>256$ & 128 & 256 & 256 & $>256$ \\
\hline 4 & $>256$ & 256 & $>256$ & $>256$ & $>256$ \\
\hline 5 & 128 & $>256$ & 256 & 128 & 128 \\
\hline Chloramphenicol & 16 & - & 4 & 64 & 8 \\
\hline Fluconazole & - & 16 & - & - & - \\
\hline
\end{tabular}

Antimicrobial activity was estimated by the inhibitory zone to five indicator microorganisms. The $>9$ mm diameter of the inhibition zone indicated that the test compound in the corresponding concentration has inhibitory activity. Indicator microorganisms: B. subtilis, Bacillus subtilis CMCC 63501; C. albicans, Candida albicans CMCC 98001; E. coil, Escherichia coli CMCC 44102; P. aeruginosa, Pseudomonas aeruginosa CMCC 10104; S. aureus, Staphylococcus aureus CMCC 26003. 
moderate antimicrobial activity. The genus Penicillium is known to be a significant source of secondary metabolites with various structures and bioactivities [16]. Previous reports on endophytic fungi also have demonstrated that members of genus Penicillium could produce a wide array of antimicrobial and antitumor agents [17]. Lin et al. found that culture broth of the endophytic fungus Penicillium sp. GQ-7 exhibited cytotoxicity in the activity screening [18]. Six new tetramic acid derivatives were further isolated, of which compound penicillenols $\mathrm{A}_{1}$ showed the strongest inhibitory activity against HL-60 cell line with $\mathrm{IC}_{50}$ values of $0.76 \mu \mathrm{M}$. Malhadas et al. have evaluated the antimicrobial potential of fungal endophytes from Olea europaea L. and found that two strains of Penicillium species have effective inhibitory activity against Gram-positive and -negative bacteria [19].

Strain Fes1712, identified as Trichoderma harzianum, showed broad-spectrum antimicrobial activity in our screening tests. Similar to Penicillium, Trichoderma species also produce many bioactive secondary metabolites, such as polyketides, terpenoids, alkaloid, butenolides, etc [20]. As such, some novel compounds were isolated from a few endophytic Trichoderma species associated with the host plants, and demonstrated a wide range of bioactivities including cytotoxic [21], anti-inflammatory [22], antibacterial [23], and antifungal activities [24, 25]. Pu et al. reported that a T. atroviride strain isolated from Camptotheca acuminate could independently produce camptothecin in the fermentation process, with yields of $197.8 \mu \mathrm{g} / 1$ [26]. In recent bioactive screening of fungal endophytes from Vinca plants, Leylaie et al. reported cytotoxic and antimicrobial activities of extracts from four Trichoderma species [27].

According to the bioactivity results, the chemical constituents extracted from fermentation of T. harzianum Fes1712 were investigated farther. In this study, EtOAc was selected as an extract solvent due to its ability to dissolve a broad range of organic compounds. Five polyketide compounds, including two new isocoumarin derivatives (1 and 2 ), two chromone derivatives (3 and 4 ) and lichexanthone (5), were isolated and identified.

Isocoumarin and its derivatives are widely distributed in various bioresources and have been shown to possess a series of biological activities due to the combination with different functional residues [28]. Engelmeier et al. confirmed that the butyl side-chain attached to C-3 of isocoumarin skeleton was a prerequisite for high antifungal activity [29]. Thongbai et al. reported that isocoumarin derivatives linked with chloropropynyl side-chain exhibited pronounced cytotoxic and only moderate antimicrobial activities [30]. However, a sugar moiety linked to the same position of isocoumarins could result in the absence of all biological activity [31]. Previous studies reported that one isocoumarin compound (3,4-dihydro-8-hydroxy-3-methylisocoumarin) was found in genus Trichoderma fungus, and showed effective antifungal activity [32]. In our study, compounds $\mathbf{1}$ and $\mathbf{2}$ were determined as two novel isocoumarin derivatives with a different butanetriol group at C-3, and showed potential inhibitory activity against Gram-negative bacteria.

Both chromone and xanthone compounds have been reported to appear in the fermentation extract of Trichoderma species [20]. Jeerapong et al. have obtained chromone derivative 3 from the crude extract of soil-derived T. harzianum F031, and reported the inhibitory activity of 3 against pathogenic fungus Colletotrichum gloeosporioides which could cause anthracnose [33]. In this bioactivity assay, compound 3 also exhibited weak inhibitory activity against fungus $C$. albicans. Compound 4 has been reported as having been isolated from actiniae-derived Trichoderma $\mathrm{sp}$. and marine brown alga-endophytic fungus T. citrinoviride, respectively [34, 35]. Lichexanthone (5) is a well-known metabolite of lichens and is also found in many filamentous fungi species [36, 37]. It has been reported to possess antimicrobial and antitumor activity [38-41]. Compound 5, as a main product, was isolated from strain Fes1712, and its broad-spectrum antibacterial activity was confirmed by bioactivity tests in this study.

\section{Acknowledgments}

This work was supported by funding obtained from Key Research \& Development Project of Shandong Province [no. 2018YYSP008], Natural Science Foundation of Shandong Province [no. ZR2017BB077, no. ZR2018BH043], the Open Foundation of the State Key Laboratory of Bioactive Seaweed Substances [no. SKL-BASS1705] and Taishan Scholar Foundation of Shandong Province.

\section{Conflict of interest}

The authors have no financial conflicts of interest to declare.

\section{Reference}

1. Gouda S, Das G, Sen SK, Shin HS, Patra JK. 2016. Endophytes: a treasure house of bioactive compounds of medicinal importance. Front. Microbiol. 7: 1538. 
2. Saikkonen K, Faeth SH, Helander M, Sullivan TJ. 1998. Fungal endophytes: a continuum of interactions with host plants. Annu. Rev. Ecol. Syst. 29: 319-343.

3. Rudgers JA, Fischer S, Clay K. 2010. Managing plant symbiosis: fungal endophyte genotype alters plant community composition. J. Appl. Ecol. 47: 468-477.

4. Rodriguez RJ, Woodward CJ, Redman RS. 2012. Fungal influence on plant tolerance to stress. pp.155-163. In Southworth D, Biocomplexity of plant-fungal interactions, Wiley-Blackwell, Oxford.

5. Kumar S, Kaushik N. 2013. Endophytic fungi isolated from oil seed crop Jatropha curcas produces oil and exhibit antifungal activity. PLoS One 8: e56202.

6. Soliman SSM, Trobacher CP, Tsao R, Greenwood JS, Raizada MN. 2013. A fungal endophyte induces transcription of genes encoding a redundant fungicide pathway in its host plant. BMC Plant Biol. 13: 93.

7. Stierle A, Strobel G, Stierle D. 1993. Taxol and taxane production by Taxomyces andreanae, an endophytic fungus of Pacific yew. Science 260: 214-216.

8. Subbulakshmi GK, Thalavaipandian A, Bagyalakshmi RV, Rajendran A. 2012. Bioactive endophytic fungal isolates of Biota orientalis (L) Endl., Pinus excelsa Wall. and Thuja occidentalis L. Int. J. Adv. Life Sci. 4: 9-15.

9. Debbab A, Aly AH, Proksch P. 2011. Bioactive secondary metabolites from endophytes and associated marine derived fungi. Fungal Divers. 49: 1-12.

10. Kharwar RN, Mishra A, Gond SK, Stierle A, Stierle D. 2011. Anticancer compounds derived from fungal endophytes: their importance and future challenges. Nat. Prod. Rep. 28: 1208-1228.

11. Maheshwari R. 2016. Fungi: experimental methods in biology. 2nd ed. CRC Press, New York.

12. Siler DJ, Cornish K. 1993. A protein from Ficus elastica rubber particles is related to proteins from Hevea brasiliensis and Parthenium argentatum. Phytochemistry 32: 1097-1102.

13. Solis MJL, Yurkov A, Cruz TE, Unterseher M. 2015. Leafinhabiting endophytic yeasts are abundant but unevenly distributed in three Ficus species from botanical garden greenhouses in Germany. Mycol. Progress 14: 1019.

14. Ding Z, Li L, Che Q, Li D, Gu Q, Zhu T. 2016. Richness and bioactivity of culturable soil fungi from the Fildes Peninsula, Antarctica. Extremophiles 20: 425-435.

15. Sharma N, Kushwaha M, Arora D, Jain S, Singamaneni V, Sharma S, et al. 2018. New cytochalasin from Rosellinia sanctae-cruciana, an endophytic fungus of Albizia lebbeck. J. Appl. Microbiol. 125: 111-120.

16. Frisvad JC, Smedsgaard J, Larsen TO, Samson RA. 2004. Mycotoxins, drugs and other extrolites produced by species in Penicillium subgenus Penicillium. Stud. Mycol. 49: 201-241.

17. Uzma F, Mohan CD, Hashem A, Konappa NM, Rangappa S, Kamath PV, et al. 2018. Endophytic fungi - alternative sources of cytotoxic compounds: a review. Front. Pharmacol. 9: 309.

18. Lin ZL, Lu ZY, Zhu TJ, Fang YC, Gu QQ, Zhu WM. 2008. Penicillenols from Penicillium sp. GQ-7, an endophytic fungus associated with Aegiceras corniculatum. Chem. Pharm. Bull. 56: 217-221.

19. Malhadas C, Malheiro R, Pereira JA, Pinho PG, Baptista P. 2017. Antimicrobial activity of endophytic fungi from olive tree leaves. World J. Microbiol. Biotechnol. 33: 46.

20. Reino JL, Guerrero RF, Hernández-Galán R, Collado IG. 2008. Secondary metabolites from species of the biocontrol agent Trichoderma. Phytochem. Rev. 7: 89-123.

21. Ding G, Wang H, Li L, Song B, Chen H, Zhang H, et al. 2014. Trichodermone, a Spiro-cytochalasan with a Tetracyclic Nucleus $(7 / 5 / 6 / 5)$ Skeleton from the Plant Endophytic Fungus Trichoderma gamsii. J. Nat. Prod. 77: 164-167.

22. Zhou P, Wu Z, Tan D, Yang J, Zhou Q, Zeng F, et al. 2017. Atrichodermones A-C, three new secondary metabolites from the solid culture of an endophytic fungal strain, Trichoderma atroviride. Fitoterapia 123: 18-22.

23. Shi XS, Wang DJ, Li XM, Li HL, Meng LH, Li X, et al. 2017. Antimicrobial polyketides from Trichoderma koningiopsis QA3 , an endophytic fungus obtained from the medicinal plant Artemisia argyi. RSC Adv. 7: 51335-51342.

24. Vinale F, Marra R, Scala F, Ghisalberti EL, Lorito M, Sivasithamparam K. 2006. Major secondary metabolites produced by two commercial Trichoderma strains active against different phytopathogens. Lett. Appl. Microbiol. 43: 143-148.

25. Liu K, Yang YB, Miao CP, Zheng YK, Chen JL, Chen YW, et al. 2016. Koningiopisins $\mathrm{A}-\mathrm{H}$, polyketides with synergistic antifungal activities from the endophytic fungus Trichoderma koningiopsis. Planta. Med. 82: 371-376.

26. $\mathrm{Pu} \mathrm{X}, \mathrm{Qu} \mathrm{X}$, Chen F, Bao J, Zhang G, Luo Y. 2013. Camptothecin-producing endophytic fungus Trichoderma atroviride LY357: isolation, identification, and fermentation conditions optimization for camptothecin production. Appl. Microbiol. Biotechnol. 97: 9365-9375.

27. Leylaie S, Zafari D. 2018. Antiproliferative and antimicrobial activities of secondary metabolites and phylogenetic study of endophytic Trichoderma species from Vinca plants. Front. Microbiol. 9: 1484.

28. Hill RA. 1986. Naturally occurring isocoumarins. Prog. Chem. Org. Nat. Prod. 49: 1-78.

29. Engelmeier D, Hadacek F, Hofer O, Lutz-Kutschera G, Nagl M, Wurz G, et al. 2014. Antifungal 3-Butylisocoumarins from Asteraceae-Anthemideae. J. Nat. Prod. 67: 19-25.

30. Thongbai B, Surup F, Mohr K, Kuhnert E, Hyde KD, Stadler M. 2013. Gymnopalynes A and B, chloropropynyl-isocoumarin antibiotics from cultures of the basidiomycete Gymnopus sp. J. Nat. Prod. 76: 2141-2144. 
31. Kornsakulkarn J, Thongpanchang C, Lapanun S, Srichomthong K. 2009. Isocoumarin glucosides from the scale insect fungus Torrubiella tenuis BCC 12732. J. Nat. Prod. 72: 1341-1343.

32. Krupke OA, Castle AJ, Rinker DL. 2003. The North American mushroom competitor, Trichoderma aggressivum f. aggressivum, produces antifungal compounds in mushroom compost that inhibit mycelial growth of the commercial mushroom Agaricus bisporus. Mycol. Res. 107: 1467-1475.

33. Jeerapong $C$, Phupong $W$, Bangrak $P$, Intana $W$, Tuchinda P. 2015. Trichoharzianol, a new antifungal from Trichoderma harzianum F031. J. Agric. Food. Chem. 63: 3704-3708.

34. Qin XY, Yang KL, Wang CY, Shao CL. 2014. Secondary metabolites of the zoanthid-derived fungus Trichoderma sp. TA26-28 collected from the south China sea. Chem. Nat. Compd. 50: 961-964.

35. Liang XR, Miao FP, Song YP, Guo ZY, Ji NY. 2016. Trichocitrin, a new fusicoccane diterpene from the marine brown alga-endophytic fungus Trichoderma citrinoviride cf27. Nat. Prod. Res. 30: 1605-1610.

36. Wang L, Zhou HB, Frisvad JC, Samson RA. 2004. Penicillium persicinum, a new griseofulvin, chrysogine and roquefortine
C producing species from Qinghai province, China. Antonie Van Leeuwenhoek 86: 173-179.

37. Yang JX, Qiu SX, She ZG, Lin YC. 2013. A new xanthone derivative from the marine fungus Phomopsis sp. (No. SK7RN3G1). Chem. Nat. Compd. 49: 31-33.

38. Ango YP, Kapche GDWF, Kuete V, Mapitse R, Yeboah SO, Ngadjui BT. 2016. Three new derivatives and others constituents from the roots and twigs of Trilepisium madagascariense DC. Helv. Chim. Acta 99: 642-649.

39. Fru CG, Sandjo LP, Kuete V, Liermann JC, Schollmeyer D, Yeboah SO, et al. 2013. Omphalocarpoidone, a new lanostane-type furano-spiro- $\gamma$-lactone from the wood of Tridesmostemon omphalocarpoides Engl. (Sapotaceae). Phytochem. Lett. 6: 676-680.

40. Pettit GR, Zhang Q, Pinilla V, Herald DL, Doubek DL, Duke JA. 2004. Isolation and structure of gustastatin from the Brazilian nut tree Gustavia hexapetala. J. Nat. Prod. 67: 983-985.

41. Wansi JD, Wandji J, Waffo AFK, Ngeufa HE, Ndom JC, Fotso S, et al. 2006. Alkaloids from Oriciopsis glaberrima Engl. (Rutaceae). Phytochemistry 67: 475-480. 